\title{
FÓRUM
}

Submetido 21.07.2020. Aprovado 18.11.2020

Avaliado pelo sistema double blind review. Editores convidados: Alessandra de Sá Mello da Costa, Ely Laureano Paiva, Marcus Vinícius Peinado Gomes e Vinicius Brei

Versão original

DOI: http://dx.doi.org/10.1590/S0034-759020200603

\section{MULHERES EM HOME OFFICE DURANTE A PANDEMIA DA COVID-19 E AS CONFIGURAÇÕES DO CONFLITO TRABALHO-FAMÍLIA}

\author{
Women in home office during the COVID-19 pandemic and the work-family \\ conflict configurations
Mujeres en home office durante la pandemia de COVID-19 y las configuraciones del conflicto trabajo y família

\section{RESUMO}

Esta pesquisa objetivou compreender os impactos que a adoção do home office, no período da quarentena da Covid-19, teve no conflito trabalho-família vivida por trabalhadoras brasileiras. Para alcançar o objetivo, foram entrevistadas 14 profissionais com diferentes arranjos familiares. Todas as entrevistadas relataram sobrecarga de trabalho devido às exigências organizacionais, às demandas com os filhos e com a casa. Apesar disso, cabe destacar que, de acordo com os depoimentos, a sobrecarga de trabalho não intensificou o conflito trabalho-família para todas, o que vai na contramão do previsto na literatura. Algumas entrevistadas alegaram que o home office aproximou-as dos filhos e maridos e propiciou mais tempo para atividade físicas e de lazer. Tal achado pode contribuir para ampliar o debate sobre o conflito trabalho-família, muitas vezes conflituosa, ao postular que não apenas o tempo, a pressão e o comportamento são fontes deste conflito, mas também a distância física que as horas dedicadas ao trabalho fora de casa requerem.

PALAVRAS-CHAVES | Conflito trabalho-família, home office, Covid-19, quarentena, dupla jornada.

\section{ABSTRACT}

The aim of this research was to understand the impacts that working from home during the COVID-19 quarantine period had on the work-family conflict for Brazilian female workers. To reach the objective, fourteen professionals with different family arrangements, were interviewed. All the interviewees reported work overload due to organizational requirements, and the demands placed on them by their children and the home. Despite this, it is worth noting that, according to the testimonies, this work overload did not intensify the work-family conflict for all or them, contrary to what is claimed in the literature. Some interviewees stated that working from home brought them closer to their children and husbands, and provided more time for physical and leisure activities. This finding can contribute towards broadening the debate on work-family conflict, by postulating that it is not only time, pressure and behavior that are the sources of this conflict, but also the physical distance that the hours spent working away from the home imposes.

KEYWORDS / Family-work conflict, telework, COVID-19, quarantine, double shift.

ANA HELOÍSA DA COSTA LEMOS aheloisa@iag.puc-rio.br 0000-0001-6222-6628

ALANE DE OLIVEIRA BARBOSA alanebarbosa@hotmail.com 000-0002-5208-8345

PRISCILA PINHEIRO MONZATO ${ }^{1}$ pripmz@gmail.com 0000-0002-5691-0711

1Pontifícia Universidade Católica do Rio de Janeiro, Escola de Negócios, Rio de Janeiro, RJ, Brasil

\section{RESUMEN}

Esta investigación tuvo como objetivo comprender los impactos que la adopción del home office, durante el período de cuarentena de la COVID-19, tuvo sobre la relación trabajo-familia de las trabajadoras brasileñas. Para alcanzar el objetivo se entrevistaron catorce profesionales, con diferentes arreglos familiares. Todas las entrevistadas relataron sobrecarga laboral debido a las exigencias organizativas, obligaciones con sus hijos y con el hogar. A pesar de ello, cabe señalar que, según los testimonios, para ninguna de ellas la sobrecarga laboral dificultó la administración de la relación trabajo-familia, al contrario de lo previsto en la literatura. Algunas entrevistadas afirmaron que trabajar en el hogar las acercó a sus hijos y maridos y les proporcionó más tiempo para actividades físicas y de recreación. Este hallazgo puede contribuir a ampliar el debate sobre la relación trabajo-familia, a menudo conflictiva, al postular que no solo el tiempo, la presión y el comportamiento son fuentes de ese conflicto, sino también la distancia física impuesta por las horas dedicadas al trabajo fuera del hogar.

PALABRAS CLAVE / Conflicto trabajo-familia, oficina en casa, COVID-19, cuarentena, doble turno. 


\section{INTRODUÇÃO}

Em 31 de dezembro de 2019, a Organização Mundial da Saúde (OMS) foi alertada sobre casos de pneumonia na cidade de Wuhan, na China, causados por um novo vírus. Poucos dias depois, a OMS declarou que o surto do coronavírus constituía uma Emergência de Saúde Pública de Importância Internacional e, em 11 de março de 2020, a Covid-19 foi caracterizada pela OMS como uma pandemia (OPAS, 2020).

Com o alerta da OMS, o Ministério da Saúde do Brasil definiu uma série de medidas a serem adotadas para o combate ao coronavírus (Agência Brasil, 2020). E, para adequar-se a essas diretrizes, muitas empresas suspenderam total ou parcialmente suas atividades ou, quando foi possível, passaram a operar na modalidade de home office. A interrupção de diversas atividades produtivas teve impactos imediatos na força de trabalho, mas esses impactos atingiram, de forma desigual, o contingente de trabalhadores/as. De acordo com Barbosa, Costa \& Hechsher (2020), trabalhadores/as que já se encontravam em condições desfavoráveis, tais como jovens, pretos/as, mulheres, pessoas pouco escolarizadas e informais, foram mais afetados/as pela crise, perdendo emprego e renda em proporções maiores do que os grupos privilegiados.

A crise produzida pela pandemia agravou o desemprego e a precarização do trabalho em curso no Brasil, nas últimas décadas (Martins, Lipp \& Monteiro Junior, 2020; Melo \& Cabral, 2020). A Pesquisa Nacional por Amostras de Domicílios (PNAD Covid-19), iniciada em maio de 2020, registrou, em setembro, um aumento de desempregados/as de $33 \%$, o que se traduz em 3,4 milhões de pessoas em busca de empregos. Os dados dessa pesquisa indicam ainda o acirramento de desigualdades históricas no mercado de trabalho brasileiro: enquanto o desemprego entre as mulheres ficou em $17 \%$, entre os homens o percentual foi de $11,8 \%$, em setembro. Entre pardos e pretos, registrou-se $16,1 \%$, contra $11,5 \%$ para brancos (IBGE, 2020).

Por afetar de forma desigual a força de trabalho, a pandemia trouxe impactos diversos para diferentes grupos ocupacionais. Se, conforme anteriormente relatado, ampliou a parcela de trabalhadores/as excluídos/as do mercado de trabalho, por outro forçou trabalhadores/as em condições mais favoráveis a adaptarem-se ao trabalho remoto, como forma de manterem seus empregos. A estratégia do trabalho remoto ou home office foi adotada por $46 \%$ das empresas brasileiras (Agência Brasil, 202ob). Todavia, a iniciativa desse tipo de trabalho acentuou a desigualdade social já mencionada. Uma pesquisa encomendada pela C6 Bank e realizada pelo Datafolha mostra que as classes A e B foram as que mais conseguiram aderir ao home office, configurando $52 \%$ dos trabalhadores desse grupo. Na classe C, esse foi o caso de apenas $29 \%$ dos profissionais; e os trabalhadores pertencentes às classes $\mathrm{D}$ e E representam percentuais ainda menores de adoção do home office: $26 \%$ (C6Bank notícias, 2020). A pesquisa ainda alerta para o aspecto de que a desigualdade na adoção do home office nas condições de pandemia reflete as desigualdades de gênero, classe e cor da pele.

A adoção repentina do home office durante a quarentena (Savic, 2020; Waizenegger, McKenna, Cai \& Bendz, 2020) obrigou os profissionais e suas famílias a adaptarem-se à nova realidade: os trabalhos domésticos se intensificaram devido à ausência dos serviços habitualmente contratados; escolas e universidades passaram a ter o conteúdo ministrado através de plataformas digitais; os encontros sociais e as atividades físicas passaram a ser feitos à distância. Tais mudanças produziram impactos diversos na vida profissional dos trabalhadores brasileiros, o que motivou a realização de estudos recentes com vistas a analisar os efeitos na produtividade do trabalho da adoção do home office, no contexto da pandemia (Mendes, Hastenreiter Filho e Tellechea, 2020).

Pesquisa realizada em abril de 2020 pelo Linkedln indicou que $62 \%$ dos entrevistados estão mais estressados com o trabalho do que antes. Estes afirmam que têm trabalhado mais horas (68\% têm trabalhado pelo menos uma hora a mais por dia, sendo que $21 \%$ chegam a trabalhar até quatro horas a mais). Além disso, $20 \%$ apontam dificuldades para conciliar as demandas do trabalho com o cuidado dos filhos. Mas, apesar dessas dificuldades, $59 \%$ dos entrevistados afirmam que, com a quarentena, têm tido mais tempo de qualidade com a família (Tobias, 2020).

0 entendimento de que a adoção do home office no contexto da pandemia produziu efeitos na relação entre trabalho e vida familiar para os trabalhadores, em geral, e para as trabalhadoras, em particular, motivou a realização da presente pesquisa que buscou compreender os impactos da adoção dessa modalidade de trabalho no conflito trabalho-família das trabalhadoras. Tal interesse é decorrente da constatação de que, no Brasil (Melo \& Thomé, 2018), cabe historicamente às mulheres a maior responsabilidade pelos cuidados com a casa e com os filhos. Dados divulgados pelo IBGE (2019) sobre "outras formas de trabalho" apontam que a taxa de realização de afazeres domésticos das mulheres foi de $92,2 \%$ ratificando sua superioridade em relação ao percentual de homens, que totalizou $78,2 \%$ (IBGE, 2019). Tais indicadores nos levaram a pressupor que a súbita necessidade de ter que trabalhar em casa, cuidar dos afazeres domésticos e dos filhos trouxe mais sobrecarga para as mulheres. 
A literatura sobre o conflito trabalho-família corrobora essa pressuposição ao evidenciar que o conflito, quando ocorre, atinge de forma mais intensa as mulheres, sobretudo aquelas que são mães (Greenhaus \& Beutell,1985; 2012; Roman, 2017). Dessa forma, o presente trabalho buscou contribuir para o debate com ênfase na questão de gênero. Cabe destacar que, embora já exista uma literatura expressiva sobre a pandemia da Covid-19, no campo da administração brasileira, a maioria dos trabalhos aborda temáticas ligadas ao turismo (Coelho \& Mayer, 2020; Trigo, 2020) e à administração pública (Santos, 2020; Costa, 2020). Raros estudos abordam os impactos da questão do home office e a ocorrência de conflitos entre trabalho e família, o que reforça a relevância de se estudar o tópico.

Para alcançar o objetivo da pesquisa, foram realizadas entrevistas com 14 mulheres, com filhos e sem filhos, casadas e solteiras. As bases conceituais, a metodologia e os resultados do estudo são apresentados nas seções seguintes.

\section{CONFLITO TRABALHO-FAMÍLIA}

O conflito trabalho-família é definido como um conjunto de pressões que ocorrem quando, ao se desempenhar os papéis profissional e pessoal, o atendimento a um papel torna difícil a conformidade com o outro (Eby, Casper, Lockwood, Bordeaux \& Brimley, 2005; Netmeyer, Boles \& Mc Murrian, 1996; Leslei, King \& Clair, 2019; Zhao, Cooklin, Richardson, Strazdins, Butterworth \& Leach, 2020).

Há evidências de que, para aqueles que têm filhos, os aspectos do trabalho invadem a vida familiar, algumas vezes de maneira positiva, considerando os ganhos financeiros, e, outras vezes, de maneira negativa, pois o tempo dedicado ao trabalho limita a atenção à família (Baxter \& Alexander, 2008). As lutas no gerenciamento do trabalho e da família ocorrem quase diariamente e têm consequências tanto para as atividades profissionais como para a vida pessoal (Pluut, Lies, Curseu \& Liu, 2018).

As principais fontes do conflito trabalho-família são: tempo, pressão e comportamento. Quanto mais importante um papel é para um indivíduo, mais tempo dedicará a ele e mais pressões e comportamentos específicos serão exigidos para desempenhar um desses papéis, o que resultará em menos tempo e energia para o outro. As obrigações em cumprir uma determinada função interferem na realização da outra e o nível de desempenho em uma função pode sacrificar a outra (Greenhaus \& Beutell, 1985).

A ocorrência de conflito é mais comum entres casais com filhos do que sem filhos e é mais frequente quando a idade dos filhos é menor que 18 anos (Baxter \& Alexander, 2008; Greenhaus
\& Beutell, 1985; Gordon e Whelan-Berry, 2004). Alguns fatores relacionados ao trabalho e à família diferem entre homens e mulheres (Beutell \& O’Hare, 2018), o que torna o gênero um fator central uma vez que as mães geralmente relatam níveis mais altos de conflito do que os pais (Minnotte, 2012; Roman, 2017; Leslei, King \& Clair, 2019). No Brasil, estudos apontam que a taxa de realização de afazeres domésticos das mulheres foi de $92,2 \%$ enquanto que os homens representam $78,2 \%$ (IBGE, 2019). Essa desigualdade de tempo e energia provoca maiores dificuldades para as mulheres dedicarem-se à área profissional (Melo \& Thomé, 2018).

No modelo de família formada por um homem e uma mulher, o apoio do marido e a dedicação às tarefas domésticas é primordial para que a mulher avance em sua carreira e consiga conciliar as esferas familiar e laboral (Gordon \& WhelanBerry, 2004; Huffman, Casper \& Payne, 2014; Lee, Zvonkovic \& Crawford, 2014). Além disso, é sabido que outros membros da família podem dar suporte para os pais, no cuidado com os filhos (Dessen \& Braz,200o). A terceirização dos cuidados dos filhos, com a contratação de babás e creches, também auxilia as mães a conciliarem a maternidade com o trabalho (Lemos \& Cavazotte, 2018).

A entrada da mulher no mercado propiciou a intensificação do conflito trabalho-família (Santujá \& Barham, 2005), o que leva muitas mães a restringirem sua participação na força de trabalho para atender às necessidades familiares (Beutell \& O'Hare, 2018; Peters \& Blomme, 2019) ou mesmo a interromperem suas carreiras (Elliot, 2002; Warner, 2013).

0 aumento da prevalência de famílias monoparentais tem sido frequentemente mencionado como uma importante mudança demográfica. No Brasil, nas últimas décadas, as mulheres estão assumindo, cada vez mais, o posto de referência nos domicílios (IPEA, 2017). No entanto, poucas pesquisas exploraram as experiências de famílias monoparentais equilibrando trabalho e família. Pesquisas com mães solteiras mostram que seus níveis de conflito tendem a ser mais altos do que das mães que vivem com parceiros (Roman, 2017; Minnotte, 2012).

O número de horas trabalhadas e a inflexibilidade cronológica têm sido associados ao conflito trabalhofamília (Greenhaus \& Beutell, 1985; Beutell \& O’Hare, 2018), consequentemente, a flexibilidade do horário de trabalho torna-se uma aliada para conciliar essas esferas. E o home office é um dos meios adotados dentro dessa ideia da flexibilidade. Todavia, nem sempre esses arranjos oferecem mais equilíbrio, levando as demandas do trabalho a interferirem no tempo disponível para a vida pessoal (Greenhaus \& Powell, 2006; Azara, Khana \& Eerdeb, 2018; Beutell \& O’Hare, 2018). 
A exaustão física está constantemente presente no conflito trabalho-família justamente por causa da sobrecarga envolvida (Pluut, et al., 2018). Além disso, podem surgir problemas como estresse, depressão, hipertensão, ansiedade, transtornos de humor e abuso de substâncias como maior consumo de álcool (Eby et al., 2005; Oliveira, Cavazotte \& Paciello, 2013).

\section{HOME OFFICE: TENDÊNCIA EM ASCENSÃO?}

Segundo a Organização Internacional do Trabalho (OIT), o trabalho remoto ou home office -- termo comumente utilizado no Brasil para designar essa modalidade -- pode ser definido como atividades realizadas em espaços diferentes dos escritórios centrais, sendo a integração entre os profissionais mediada por tecnologias digitais como smartphones, laptops e computadores desktop, entre outros. Cabe destacar que as expressões telework, home office, virtual work, telecommuting e remote work são indiscriminadamente empregadas quando se associa o trabalho desenvolvido fora do cenário laboral tradicional (OIT, 2017; Zerbini \& Zerbini, 2020). Nos últimos anos, o home office ganhou força entre os brasileiros: entre 2016 e 2017 o número de adeptos aumentou 16,2\% e entre 2017 e 2018 cresceu 21,1\% (Agência Brasil, 2020b).

A literatura sobre o tema destaca que o home office apresenta vantagens, pois permite melhor acomodação entre os horários dedicados ao trabalho e às responsabilidades domésticas e familiares, trazendo maior produtividade e melhor equilíbrio entre essas esferas. Ademais, sua adoção reduz os custos com o transporte casa-trabalho. Como desvantagem menciona-se a tendência à superindividualização do trabalho, o que pode gerar isolamento social, profissional e político. 0 aumento das horas dedicadas ao trabalho também é reportado como consequência negativa do home office (Ferreira Jr., 2000; OIT, 2017; Haubrich \& Froehlich, 2020).

Não são todos os profissionais que se adaptam ao home office, pois este requer autodisciplina, organização, autonomia e prazer em trabalhar sozinho (Haubrich \& Froehlich, 2020). Os profissionais com filhos pequenos enfrentam mais dificuldades para trabalhar em casa, o que indica que essa opção não é conveniente, para muitos (Habib \& Conrford, 1996).

O home office implementado em decorrência da pandemia da Covid-19 é um arranjo eventual, pois foi a modalidade de trabalho adotada por muitas empresas para contornar a crise (Agência Brasil, 2020b). As pessoas que estão trabalhando em casa muitas vezes tiveram horários de trabalho modificados e possuem grandes chances de interrupções e distrações com a presença da família que também se encontra em casa devido à pandemia (Spurk \& Straub, 2020).

\section{METODOLOGIA}

Para alcançar o objetivo de pesquisa, optou-se por uma investigação de natureza qualitativa, tendo sido entrevistadas 14 mulheres, com idades entre 33 e 55 anos, por meio de uma plataforma de comunicação digital, em junho de 2020. A maioria das entrevistadas é do Rio de Janeiro, todas trabalhavam de modo presencial e se adaptaram ao home office devido à pandemia. Como perfil, buscou-se por profissionais com carreiras consolidadas, atuantes em diferentes segmentos econômicos. $\mathrm{O}$ acesso a essas mulheres deu-se por meio de círculos de relacionamentos, complementado pela técnica "bola-de-neve". Dentre as entrevistadas há mulheres casadas, solteiras, viúvas e divorciadas com e sem filhos. As entrevistas aconteceram com base em um roteiro semiestruturado, com perguntas que versavam sobre a rotina de trabalho antes e depois da pandemia e sobre as estratégias utilizadas para conciliar trabalho e vida pessoal/familiar, no novo contexto.

As entrevistas foram gravadas e duraram de 20 a 40 minutos. Os relatos obtidos foram analisados por meio da análise de conteúdo (Bauer \& Gaskell,2002), com vistas a identificar os elementos que permitissem responder à principal indagação dessa pesquisa: quais os efeitos produzidos no conflito trabalhofamília de trabalhadoras em decorrência da adoção do sistema home office, no contexto da quarentena da Covid-19? A tabela 1 apresenta os perfis e nomes fictícios das entrevistadas.

\section{ANÁLISE E DISCUSSÃO DOS RESULTADOS}

Esta pesquisa buscou compreender os impactos que a adoção do home office teve no conflito trabalho-família de trabalhadoras, no período da quarentena da Covid-19.

Ao se analisar os depoimentos obtidos, o primeiro ponto a merecer destaque diz respeito ao fato de todas as entrevistadas terem relatado aumento de volume de trabalho, no período investigado. Tal afirmação não causa surpresa, pois a condição excepcional em que se deu a passagem para o home office conjugou as exigências do trabalho corporativo com as demandas dos cuidados da casa e dos filhos, no caso daquelas que são mães. Ademais, o confinamento social imposto fez com que toda a família ficasse em casa, simultaneamente. A sobrecarga de trabalho deveu-se, em parte, à necessidade das 
entrevistadas se dedicarem às tarefas domésticas, posto que dispensaram os serviços de suas empregadas e faxineiras e, também, à atenção com os filhos que passou a ser requerida, já que estes passaram a estudar em casa, remotamente. Além desses aspectos, as condições abruptas em que se deu a passagem para o trabalho remoto (Savic, 2020; Waizenegger, McKenna, Cai \& Bendz, 2020), sem planejamento ou preparação prévia, na contramão do preconizado pela literatura sobre o tema (Haubrich e Froehlich, 2020), apesar de compreensíveis no contexto estudado, também aumentaram as dificuldades das entrevistadas. Algumas se viram sem recursos materiais adequados para o trabalho, como computadores e mobiliário; outras se ressentiram da falta de organização do trabalho, o que gerou ainda mais sobrecarga.

Tabela 1. Perfil das entrevistadas

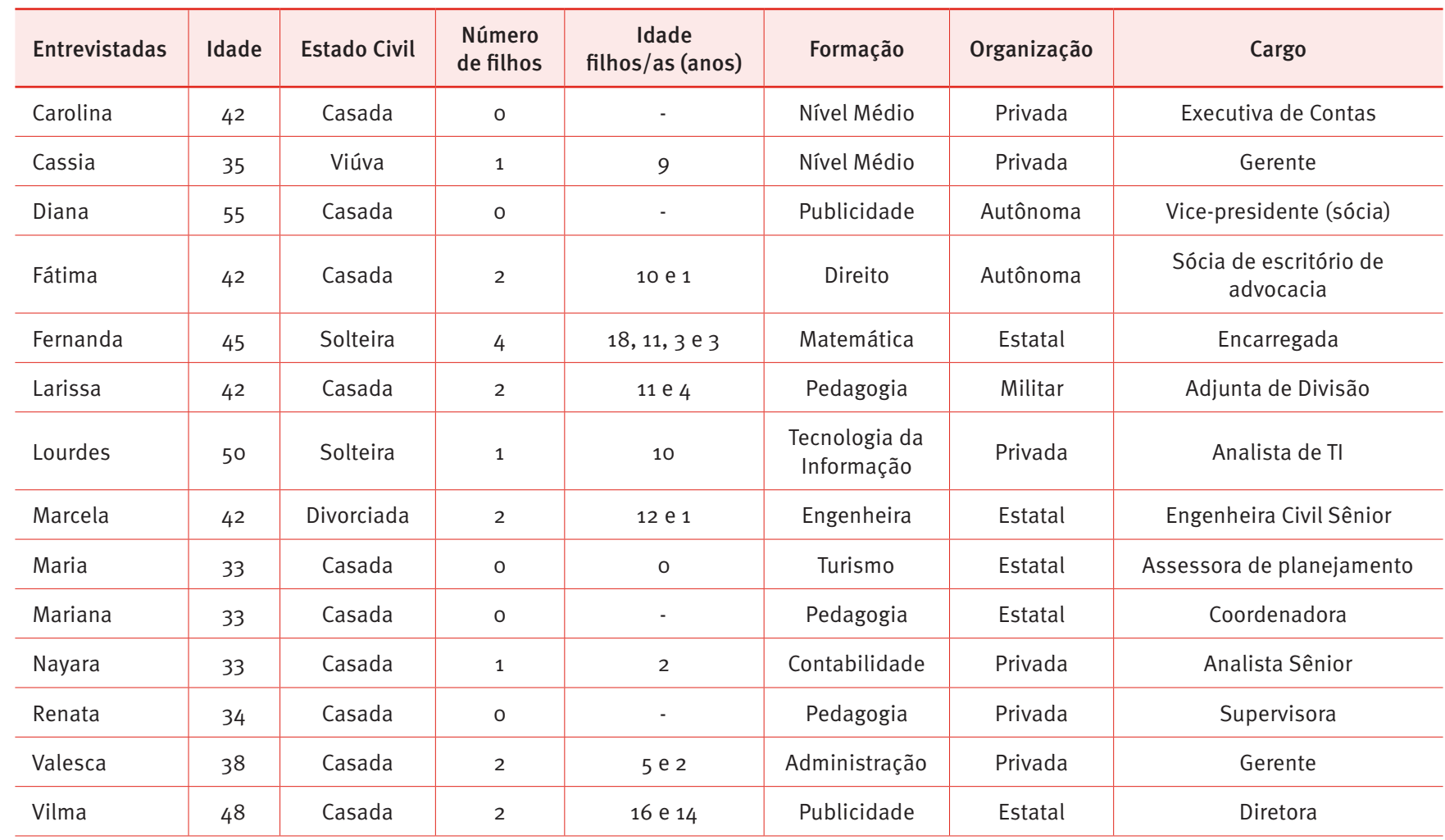

Mas o aumento da carga de trabalho vivido pelas entrevistadas não intensificou o conflito trabalho-família para todas, como se poderia supor com base nos achados da literatura sobre o tema (Greenhaus \& Beutell, 1985; Beutell \& O’Hare, 2018). De fato, uma parte das entrevistadas confirmou essa situação: sobrecarregadas com cuidados da casa, dos filhos e com as exigências do trabalho, elas relataram que não estão dando conta de atender às múltiplas demandas e se mostraram bastante angustiadas com a vivência atual. Alegam que não conseguem fazer nada a contento: não cuidam da casa e dos filhos como desejariam e não atendem às demandas do trabalho, como deveriam. Estressadas, algumas recorrem ao consumo cotidiano de álcool para desanuviar. Nesse sentido, seus relatos corroboram os pressupostos que inspiraram este trabalho e que apontam para um acirramento do conflito, no contexto da quarentena.
Entretanto, parte das entrevistadas, apesar de também se sentir sobrecarregada, não parece ter vivenciado a experiência de home office como intensificadora do conflito trabalhofamília (Ferreira, 2000; Haubrich \& Froehlich, 2020; OIT, 2017). Na contramão do que a literatura sobre o tema nos levaria a pressupor, elas alegam que estão gostando da vivência, pois estão mais próximas dos filhos e dos maridos, além de terem mais tempo para atividades físicas e de lazer. Tal constatação nos levou a querer entender melhor as nuances por trás dessas experiências díspares: acirramento do conflito trabalho-família, para parte das entrevistadas, e atenuação do conflito, para outra parte, a julgar pelos depoimentos. Para aprofundar essa discussão foram criados dois tópicos: o primeiro discute os motivos que levaram algumas entrevistadas a aumentar suas vivências de conflito; o segundo, aborda as condições que amenizaram o conflito. 


\section{Home office na quarentena e intensificação do conflito trabalho-família}

Conforme destacado, parte das entrevistadas, assoberbadas pelas múltiplas demandas de trabalho geradas no contexto do home office da quarentena - trabalho corporativo, doméstico, e/ ou cuidado dos filhos -- se mostraram insatisfeitas com a situação vivida. Esse grupo é formado por Marcela, Fernanda, Larissa, Maria, Mariana e Fátima. Marcela, 42 anos, divorciada e com uma filha de 12 anos e outra de 1 ano, relata a dificuldade de conciliar as duas esferas com uma frase emblemática:

“Impossível, eles sabem que é impossível! O meu chefe, graças a Deus é um cara lega. Não é que eu esteja de má vontade, que eu sou uma empregada encostada, nunca fui, mas estou em uma situação que é impossível (...) participo de reunião assim como tô falando com você; o áudio só ligo quando vou falar e mesmo assim tem vezes que ela (filha de 1 ano) tá aqui gritando".

Fernanda, também solteira e com quatro filhos com idades de 18, 11 e gêmeos de 3 anos, expõe sua situação:

“Eu me sinto mal por isso, porque eu não tô participando de nada; ao mesmo tempo eu tenho a compreensão da equipe, mas não sei até quando. Eu não me sinto bem (...) quando chegou a ferramenta pra eu trabalhar eu não tive mais a ferramenta porque é disputada por três pessoas nessa casa, mas não consigo me concentrar; eles (os gêmeos) ficam aqui pendurados atrás de mim."

Esses dois relatos evidenciam as dificuldades em atender às demandas do trabalho vividas por essas duas entrevistadas que são mães de crianças pequenas, condição que é destacada na literatura como intensificadora do conflito (Greenhaus \& Beutell, 1985; Gordon \& Whelan-Berry, 2004). Ademais, o fato de não viverem com os pais de seus filhos aumenta suas dificuldades, aspecto apontado nos estudos que destacam que mulheres com essa configuração familiar enfrentam desafios ainda maiores para conciliar as esferas domésticas/familiares com a profissional (Minnotte, 2012; Roman, 2017). Essas entrevistadas não estão conseguindo se dedicar ao trabalho como precisariam, tendo que contar com a boa vontade de chefias e equipes, algo que provavelmente se dá, apenas, pela excepcionalidade do contexto pandêmico. Tampouco conseguem dar atenção adequada aos filhos. Nos casos relatados, as entrevistadas não se frustram apenas com a baixa performance no trabalho, mas também com a falta de atenção aos filhos:

"Às vezes nem me dedico tanto mesmo em casa, tô sempre me cobrando, mas tem dias que não leio pra eles, tem dias que não brinco, porque já enchi o saco ou não tô com paciência, nem estando com eles significa que tô com o tempo bom de dedicação". (Fernanda, solteira, quatro filhos com idades de 18,11 e gêmeos de 3 anos)

Mas não são apenas as mulheres com essa configuração familiar que relatam aumento do desequilíbrio entre as esferas familiar e profissional, vividas nesse contexto. Larissa e Fátima, casadas e com filhos, também se ressentem da nova situação:

"Eu tô ficando bem mais cansada; além dessas coisas (tarefas domésticas) tem que ficar o tempo todo de olho nos deveres do (filho)...eu só acompanhava, então era mais fácil; agora não, você tem que assistir o vídeo, tem um vai e volta, tem que fazer o trabalho, rever o vídeo." (Larissa, filho de 11 anos e filha de 4 anos)

“Teve vezes de eu tá trabalhando e daqui a pouco falar 'meu Deus! Caramba! Ele tem que jantar.' Aí quando eu pego ele no berço, a criança está toda mijada porque fiquei tão focada no trabalho [...] e o tempo passou demais. Eu tenho vontade de chorar quando isso acontece". (Fátima, filho de 10 anos e de 1 ano)

Conforme observado nos relatos, apesar de a presença de filhos pequenos em casa ser um fator que amplifica o conflito vivido por essas mulheres, Maria e Mariana casadas, mas sem filhos e ocupantes de cargos gerenciais, tampouco se mostraram satisfeitas com o home office:

"A sobrecarga do trabalho que causou a pandemia no meu setor, eu não tô tendo tempo pra fazer outras coisas, não consigo equilibrar essa função de casa, a falta de estrutura pra trabaIhar em casa, pra gerenciar as pessoas que trabalham com você, isso é pior ainda".(Maria) 
“...hoje eu atuo como coordenadora de uma equipe [...] eu tinha que dar diretrizes de algo que eu não fui preparada para e eu nem sabia como eu mesma ia lidar" (Mariana)

A dificuldade em conciliar o trabalho com a esfera doméstica e familiar, no caso das entrevistadas que são mães, mas vivem sozinhas com filhos pequenos, pode ser explicada, em grande medida, pelo fato de não haver outro adulto em casa para dividir os cuidados com os pequenos (Minnotte, 2012; Roman, 2017). Cabe destacar que o contexto da quarentena ampliou essa dificuldade, pois as aulas foram suspensas, as creches fechadas e as empregadas e babás, dispensadas. Sem muita ajuda, essas profissionais tiveram que cuidar, sozinhas, dos filhos e da casa, o que impactou fortemente em seu desempenho no trabalho.

$\mathrm{Na}$ tentativa de conciliar essas diferentes esferas, as entrevistadas tiveram que criar algumas estratégias: Marcela e Fernanda contam com a ajuda dos filhos mais velhos para conseguirem fazer as múltiplas atividades:

Então eu peço pra ela (filha de 12 anos) pra ficar com a (filha de 1 ano) pra eu lavar a louça, (...) passar um pano na casa, estender roupa no varal." (Marcela)

Todavia, cabe destacar que a presença do parceiro em casa não é garantia de uma divisão mais equilibrada das tarefas domésticas:

“...ele precisa que eu mande e gerencie, é chato pra caramba, eu vejo boa vontade nele, mas é assim: o que eu vou fazer pra janta? Quando a gente vai varrer? Toda essa organização quem faz sou eu. Não tô conseguindo equilibrar, acho que minha casa é só obrigações(...) eu tô louca pra voltar a trabalhar presencialmente, porque a pandemia pra mim tá sendo horrível” (Maria, casada, sem filhos)

A falta de participação do marido nessas atividades é relatada de forma dramática por Fátima:

"Tinha dia de fazer a faxina chorando, sozinha, e ele deitado na cama vendo televisão [...] ele não me ajudava era muito porque ele queria que eu fizesse que a empregada viesse." (Fátima, casada, dois filhos)
O aumento do estresse vivido na quarentena levou ao maior consumo de álcool, recurso usado por algumas dessas mulheres para suportar a pressão (Eby et al., 2005; Oliveira, Cavazotte \& Paciello, 2013):

"Eu sempre gostei de beber aos finais de semana e na pandemia não tem dia; pra sair do estresse, ter um momento de relaxamento eu estava indo pra cerveja todos os dias, o consumo de álcool aumentou." (Fernanda, solteira, quatro filhos)

"Beber então nem se fala, [...] a gente acaba bebendo para relaxar." (Fátima, casada, dois filhos)

Os depoimentos dessas mulheres corroboram, em grande medida, a literatura que aponta que o conflito trabalho-família é maior para mulheres que têm filhos pequenos (Greenhaus \& Beutell, 1985; Gordon e Whelan-Berry, 2004). Esse conflito se deve ao acúmulo de tarefas do trabalho e de cuidado da casa e dos filhos que ocorreu durante a quarentena. Porém, merece destaque o fato de duas mulheres casadas, à semelhança das solteiras, se sentirem sobrecarregadas com as tarefas de cuidado: seus maridos pouco participam dessas atividades, chegando ao caso extremo de Fátima que não conta com nenhuma colaboração do marido. Seus casos confirmam os achados dos estudos que destacam que cabe historicamente às mulheres a maior responsabilidade pelos cuidados com a casa e com os filhos (Gordon \& Whelan-Berry, 2004; Lee, Zvonkovic \& Crawford, 2014; Melo \& Thomé, 2018). No caso das mulheres casadas, essa desigualdade é evidente, pois, embora seus parceiros estejam em casa, o peso dos afazeres domésticos recaiu em seus ombros.

\section{Home office na quarentena e atenuação do conflito trabalho-família}

Conforme anteriormente mencionado, apesar de sobrecarregadas, parte das entrevistadas alega ter encontrado, na nova situação, condições para equilibrarem melhor a relação entre o trabalho e a vida familiar. Na contramão do que costuma ser ressaltado na literatura sobre o tema (Greenhaus \& Beutell, 1985; Beutell \& O'Hare, 2018), o aumento da carga de trabalho corporativo e doméstico não reforçou a vivência de desequilíbrio, a julgar por seus relatos. Essa constatação reforçou o interesse em entender as condições que viabilizaram tal experiência. Esses aspectos são explorados nesta seção. 
Dentre as entrevistadas que reportaram maior equilíbrio entre as esferas de trabalho e vida pessoal/familiar há três sem filhos: Renata, Carolina e Diana. A ausência de crianças pequenas em casa e a participação dos maridos nas atividades domésticas explica, em grande medida, a não intensificação do conflito para essas mulheres. Seus relatos apontaram que a participação masculina nos cuidados com a casa e com filhos aumentou durante a pandemia. Conforme destaca a literatura, a participação dos parceiros é chave para a conciliação das esferas laboral e doméstica, para as mulheres que trabalham (Huffman, Casper \& Payne, 2014; Lee, Zvonkovic \& Crawford, 2014). Renata, casada e sem filhos, descreve a nova rotina:

"Eu tenho um trabalho mais monitorado, com reuniões, acabo ficando mais ocupada durante o dia e meu marido tem o horário bem mais flexível porque trabalha junto com o sócio e por demanda. Então enquanto eu tô em reunião de manhã, ele prepara o café da manhã, e se tem alguma coisa pra adiantar pro almoço ele já adianta."

No caso de Diana, casada e sem filhos, a participação do marido nas tarefas domésticas já ocorria, o que permitiu uma condição mais favorável no equilíbrio entre vida familiar e profissional:

“Tarefas domésticas a gente divide até bem, o (marido) nesse aspecto é até participativo, (...) eu não tive grandes dificuldades frente aos grupos de mulheres que eu escuto(...) eu sou meditante, essas coisas ajudam, deixam você um pouco mais equilibrada“

Carolina, também casada e sem filho, viveu uma experiência semelhante à de Renata e Diana, relatando o saldo positivo desse novo arranjo:

"Consigo dar mais resultado que antes, tiro minha pestana, assisto novela, faço minha esteira, faço Pilates com minha mãe e minha irmã por chamada de vídeo, [...] pra mim tá incrível isso."

Mas chamou a atenção o fato de que não foram apenas as entrevistadas sem filhos e casadas com parceiros que realizam afazeres domésticos que vivenciaram um maior equilíbrio entre as esferas familiar e profissional. Entrevistadas com filhos, solteiras e casadas, também relataram que o trabalho em home office, durante a quarentena, contribui para conseguir maior equilíbrio. A fala de Nayara, casada e com uma filha de 2 anos, resume o novo cenário:

"Eu tô com uma sobrecarga maior de trabalho, mas eu também tô satisfeita por ter mais tempo com a minha filha e com meu marido, coisa que não tinha porque era só fim de semana praticamente, por passar o dia todo fora. A gente acaba ficando mais tempo junto e isso é bem interessante."

Vilma, casada e com dois filhos, de 16 e 14 anos, também vê aspectos positivos na nova situação:

"Estou trabalhando muito mais...tanto as tarefas domésticas eu trabalho mais, como as do trabalho, mas ainda assim estou preferindo porque eu consigo fazer os horários, eu consigo me planejar."

Valesca, casada, com dois filhos, contou com maior participação do marido nas tarefas de cuidado dos filhos, durante a pandemia, e também relatou adaptação ao home office:

“A minha rotina era muito ausente da minha vida pessoal (...) mas no momento de pandemia o meu mais novo teve febre e eu pude estar ao lado dele, dar um carinho, um colo, coisa que antes eu não conseguia."

Nesse sentido, a flexibilidade de horário de trabalho que o home office propicia parece configurar-se em fator favorável para a conciliação trabalho-família, ao menos para parte das entrevistadas (Ferreira Jr., 2000; OIT, 2017; Beutell \& O’Hare, 2018; Haubrich \& Froehlich, 2020).

Mesmo vivendo sozinhas com seus filhos e não contando com a ajuda de parceiros, o que as deixa ainda mais sobrecarregadas, Cassia e Lourdes valorizam a maior proximidade física com as filhas que o trabalho em home office na quarentena, propiciou. Apesar de trabalharem mais:

“Eu acho que tô trabalhando mais(... porque agora as coisas se prolongam um pouco mais, não tá todo mundo junto, então a informação demora mais a ser passada de uma pessoa pra outra",

Cassia valoriza, sobretudo, o fato de estar mais próxima da filha única de 9 anos: 
"Eu tenho mais tempo com ela, consigo ver um filme com ela, o que eu fazia muito pouco; eu consigo almoçar com ela, coisa que só fazia final de semana."

Lourdes, mãe de uma menina de 10 anos, sente-se igualmente sobrecarregada, mas o fato de estar mais perto da filha e de poder participar mais de sua rotina a leva a comemorar:

“Meu trabalho optou pela redução de jornada de trabalho. Estamos ainda trabalhando $25 \%$ de redução, então isso significa dizer que eu estou trabalhando 6 horas só que na prática não é bem assim... nas últimas duas semanas eu estou trabalhando 11 a 12 horas. [...]Agora vai ser $100 \%$ home office e eu estou adorando, adorando!" (Lourdes, solteira, uma filha)

Mas cabe destacar que, à exceção de Diana, que teve as demandas profissionais reduzidas no período da quarentena em função do setor em que atua, todas as demais reconheceram que a carga de trabalho aumentou. Nesse sentido, o relato de Lourdes, que está "adorando" o home office, é significativo:

“Eu estava extremamente cansada, não vou negar porque tenho home office, tendo que lidar com o novo que foi o on-line das aulas dela (filha), tendo que [...]ver o que que eu ia comer com ela, eu tinha que pedir comida." (Lourdes, solteira, uma filha).

Apesar de ter a casa como local de sobreposição de funções (Ferreira Jr., 2000; OIT, 2017; Haubrich \& Froehlich, 2020), essas mulheres parecem ter suportado melhor a sobrecarga do home office durante a quarentena por terem podido viver, também, momentos com a família que foram possíveis graças à proximidade física contingente ao contexto estudado.

\section{CONSIDERAÇÕES FINAIS}

Delineada com o objetivo de compreender os impactos que a adoção do home office, no período da quarentena da Covid-19, teve no conflito trabalho-família de trabalhadoras, a presente pesquisa trouxe alguns achados para o debate acerca dos conflitos presentes, que são explorados, a seguir.

A totalidade das entrevistadas acusou crescimento do volume de trabalho. Todavia esse aumento não pode ser atribuído, apenas, ao aumento da carga de trabalho corporativo decorrente da adoção do home office, nos termos descritos na literatura (Ferreira Jr., 2000; OIT, 2017; Haubrich \& Froehlich, 2020). Ainda que tal fato esteja presente em muitos relatos, o contexto da quarentena trouxe mais sobrecarga para as entrevistadas, posto que, além de se dedicarem ao trabalho remoto, tiveram que cuidar da casa e dos filhos, simultaneamente. A dispensa das empregadas e faxineiras obrigou-as a realizar tarefas que nem sempre faziam e o fechamento das escolas e creches demandou mais atenção aos filhos, que ficaram integralmente, em casa. Nesse contexto excepcional, chamou atenção o fato de muitas relatarem que seus parceiros passaram a participar mais das atividades domésticas. Apenas Renata, Diana, Vilma e Mariana afirmaram que sempre dividiram com o marido as tarefas da casa; as demais alegaram que o parceiro passou a "ajudar mais", nesse período, expressão usada por muitas para se referir a essa participação, que ratifica o entendimento de que tais atividades são fundamentalmente responsabilidade delas. Cabe, no entanto, indagar se essa “ajuda” estará presente no cenário pós-pandemia ou se terá sido apenas uma participação associada à excepcionalidade do contexto.

O peso do machismo não apareceu apenas no uso da palavra "ajudar”. Maria e, sobretudo, Fátima, não contaram com muita "ajuda" de seus maridos, o que tornou a vivência de home office mais penosa. 0 acúmulo de atividades pesou muito para as entrevistadas solteiras e com filhos pequenos, fato mais do que compreensível, pois a dispensa de suas funcionárias deixou-as diante da tripla tarefa de cuidar dos filhos, da casa e das demandas profissionais. Nos termos de Marcela, tal combinação é “impossível”. Conforme anteriormente destacado, para um conjunto expressivo de entrevistadas, o acúmulo de atividades que caracterizou o período da quarentena intensificou o conflito trabalho-família, achado este que vai ao encontro de boa parte da literatura sobre o tema, que descreve este acúmulo como potencializador do conflito (Minnotte, 2012; Pluuit, et al., 2018; Roman, 2017).

Todavia, merece destaque o fato de parte significativa das entrevistadas, que também sentiu sua carga de trabalho aumentar, ter apontado ganhos nessa situação. Carolina, por exemplo, disse que está “achando incrível” e Lourdes, que está “adorando". Para a maioria das casadas, sem filhos, a experiência permitiu um maior equilíbrio entre as diferentes atividades exercidas e a sobrecarga de trabalho reportada por elas refere-se, sobretudo, ao trabalho corporativo. A ausência de filhos explica, em grande medida, essa realidade (Greenhaus \& Beutell, 1985; Gordon \& Whelan-Berry, 2004; Baxter \& Alexander, 2008). Somada a este fato, a maior participação dos maridos na execução das atividades domésticas, no contexto da quarentena, atenuou a sobrecarga proveniente 
dessas tarefas, o que permitiu que as mulheres tivessem mais tempo para si e para estar com os parceiros.

Mas o achado que nos surpreendeu diz respeito ao fato de algumas entrevistadas com filhos, casadas ou não, terem relatado, simultaneamente, aumento da carga de trabalho e maior satisfação com o convívio familiar propiciado. $\mathrm{Na}$ contramão da literatura que destaca que a falta de tempo é uma das principais fontes do conflito trabalho-família (Greenhaus \& Powell, 2006; Azara, Khana \& Eerdeb , 2018; Beutell \& O’Hare, 2018), para essas mulheres o trabalho em home office, durante a quarentena, ao invés de intensificar o conflito, amenizou-o. Argumentamos que, tal achado, traz uma contribuição relevante para o debate. Aparentemente, para essas profissionais, a sobrecarga de trabalho foi suportada e relativizada, tendo em vista a oportunidade, propiciada pelo home office, de ficarem mais perto da família. Possivelmente acostumadas a gerenciar uma sobrecarga usual de trabalho, essas mulheres valorizaram mais a proximidade física com a família que a nova rotina possibilitou, do que o aumento de trabalho dela decorrente.

Nesse sentido, em linha com a literatura que destaca a flexibilidade que o home office traz (Spurk, Daniel; Straub, Caroline, 2020), constatou-se que este arranjo permitiu que elas tivessem mais convívio com a família, principalmente durante as refeições e entre as pausas do trabalho. A combinação flexibilidade e proximidade física permitiu que Valesca cuidasse do filho com febre e que Lourdes assistisse à apresentação da filha, experiências que não teriam sido vividas se estivessem no trabalho convencional. Chamou a atenção o fato de que a não delimitação das fronteiras entre o espaço do trabalho e do não trabalho, que aparece na literatura como uma das causas da intensificação do conflito (Peters \& Blomme, 2019), ter, nesses casos, contribuído para amenizá-lo.

Para ampliar o debate sobre o tema, merece destaque a consideração de que não apenas o tempo, a pressão e o comportamento intensificam o conflito (Greenhaus \& Beutell, 1985), mas também a distância física parece impactá-lo. O entendimento do impacto desse quarto fator: a distância física da família que as horas dedicadas ao trabalho fora de casa exigem ajudaria a explicar o fato de que, apesar da sobrecarga de trabalho, parte das entrevistadas terem vivenciado tal experiência como atenuadora do conflito trabalho-família. Tal constatação reforça o entendimento de que as profissionais que são mães desejam exercer ambas atividades, profissional e materna, mesmo às expensas de sobrecarga de trabalho, e que a combinação flexibilidade e proximidade física da família que o home office na quarentena propiciou foi valorizada pelas entrevistadas inseridas em contextos familiares mais equilibrados.
Todavia, não podemos perder de vista que várias entrevistadas que são mães reportaram esgotamento e dificuldade em trabalhar. Essa constatação traz um alerta para a discussão que se avizinha sobre a implementação ampliada do home office no contexto pós-pandemia: ainda que este modelo de trabalho possa trazer ganhos para alguns(as) empregados(as) e empregadores/as, sua adoção de forma homogênea para o conjunto da força de trabalho, desconsiderando as particularidades dos diferentes arranjos domésticos/ familiares, pode acirrar, ainda mais, as desigualdades entre trabalhadores(as).

De forma conclusiva, a observação de que o trabalho em home office parece atender aos anseios de conciliação dessas duas esferas, ao menos para parte das entrevistadas, indica que tal modalidade deva ser considerada pelas organizações que se querem mais inclusivas, ainda que tal discussão precise ser ponderada em função dos diferentes arranjos familiares de sua força de trabalho.

Cabe destacar, como limitação do presente estudo, o fato de que, em decorrência do perfil pesquisado e da forma de acessar as participantes, há considerável homogeneidade no conjunto de entrevistadas, pois todas são mulheres heterossexuais, brancas e da chamada classe média. Nesse sentido, os achados da pesquisa refletem as especificidades desse subgrupo de mulheres. A especificidade do contexto estudado -- a quarentena da Covid-19 -- também traz limitações, pois esta tanto agravou a sobrecarga de trabalho, como aumentou a participação masculina nas tarefas domésticas. Assim, sugere-se que pesquisas futuras aprofundem os impactos da adoção do home office no conflito trabalho-família de mulheres com diferentes configurações familiares, mas em contexto não atípico, como o estudado.

\section{REFERÊNCIAS}

Agência Brasil (2020). Covid-19: Veja como cada estado determina o distanciamento social. Recuperado de: https://agenciabrasil.ebc. com.br/saude/noticia/2020-04/covid-19-veja-como-cada-estadodetermina-o-distanciamento-social

Agência Brasil (2020b). Home office foi adotado por $46 \%$ das empresas durante a pandemia. Recuperado de: https://agenciabrasil.ebc. com.br/economia/noticia/2020-07/home-office-foi-adotado-por46-das-empresas-durante-pandemia

Azara, S., Khana, K. \& Eerde, W.V. (2018).Modeling linkapes between flexible work arrangements. Journal of Business Research, 91, 134 143. doi: 10.1016/j.jbusres.2018.06.004 
Barbosa, A. L. N. H.; Costa, J. S.; Hecksher, M. (2020). Mercado de trabalho e pandemia da covid-19: Ampliação de desigualdades já existentes? In: Mercado de Trabalho: conjuntura e análise, n.69, p.55-63. Recuperado de https://www.ipea.gov.br/portal/index. php?option $=$ com_content $\&$ view $=$ article $\& i d=36187 \&$ ltemid $=9$. doi: 10.13140/RG.2.2.18383.10408

Bauer, M. \& Gaskell, G.(2002). Análise de conteúdo clássica: Uma revisão. In: M. Bauer and G. Gaskell (orgs.), Pesquisa qualitativa com texto, imagem e som: um manual prático (pp. 189-217).

Beutell, N., \& O'Hare (2018). M.Work Schedule and Work Schedule Control Fit: Work-Family Conflict, Work-Family Synergy, Gender, and Satisfaction (January, 19). Recuperado de SSRN Journal. doi:10.2139/ ssrn.3105671

C6 Bank notícias (2020): Datafolha/C6 Bank: Pandemia é pior para mulheres, pretos e pardos e classes mais baixas. Recuperado de: https://medium.com/c6banknoticias/datafolha-c6-bank-pandemia-\%C3\%A9-pior-para-mulheres-pretos-e-pardos-e-classesmais-baixas-ca116bfd6643

Coelho, M.F., \& Mayer, V.F. (2020). Gestão de Serviços Pós-Covid: 0 que se Pode Aprender com o Setor de Turismo e Viagens? Gestão e Sociedade, 14(39)3698-3706. doi: 10.21171/ges.v14i39.3306

Costa, S. S.(2020). Pandemia e Desemprego no Brasil. Revista de Administração Pública, 54(4), 969-978. doi: 10.1590/0034 761220200170

Dessen, M. A\& Braz, M. P. (2000). Rede Social de apoio durante transições familiares decorrentes do nascimento de filhos. Psicologia: Teoria e Pesquisa, 16(3), 222-231. doi:10.1590/S0102-37722000000300005.

Eby, L.T., Casper, W.J., Lockwood, A., Bordeaux, C. \& Brimley, A.(2005). Work and family research in IO/OB: Content analysis and review of the literature (1980-2002). Journal of Vacational Behavior, 66(1),124197. doi: 10.1016/j.jvb.2003.11.003

Ferreira Junior, J.C.(2000). Telecommuting: o Paradigma de um Novo Estilo de Trabalho. RAE-Revista de Administração de Empresas, 40(3),8-17. doi:10.1590/S0034-75902000000300012

Greenhaus, J.H., \& Beutell, N.J.(1985). Sources of conflict between work and family roles. Academy of Management Review, 10(1),76-88. doi: 10.5465/amr.1985.4277352

Greenhaus, J. H., \& Powell, G. N.(2006). When work and family are allies: A theory of work-family enrichment. Academy of Management Review, 31(1),72-92. doi: 10.5465/amr.2006.19379625

Gordon, J.R., \&Whelan-Berry, K.S.(2004).It takes two to tango: An empirical study of perceived apousal / patner sipport for working women. Women in Management Review, 19(5), 260-273. doi: 10.1108/09649420410545980

Habib, L. \& Cornford, T.(1996).The virtual office and Family life. London School of Econimic, 296-304. doi: 10.1145/238857.238911

Haubrich, D. B., \& Froehlich, C. (2020).Benefícios e Desafios do 'Home office' em Empresas de Tecnologia da Informação. Gestão \& Conexões, 9(1),167-184. doi: 10.13071/regec.2317-5087.2020.9.1.27901.167-184

Huffman, A.H., Casper, W.J. \& Payne, S.C. (2014).How does spouse career support relate to employe turnover? Work interfering with family and job satisfaction as mediators. Journal of Organizational Behavior, 35, 194-212. doi: 10.1002/job.1862

IBGE (2019). Pesquisa traz dados referentes à divisão de tarefas domésticas. Recuperado de: https://www.cnm.org.br/comunicacao/ noticias/pesquisa-traz-dados-referentes-a-divisao-de-tarefasdomesticas

IBGE (2020).Pesquisa Nacional por amostra de domicílio PNAD Covid 19, Setembro 2020, Resultado mensal. Recuperado de https:// biblioteca.ibge.gov.br/visualizacao/livros/liv101763.pdf

Lee, N., Zvonkovic, A.M. \& Crawford, D.W (2014).The impact of work conflict and facilitation on women's perceptions of role balance. Journal of Family Issues, 35(9), 1252-1274. doi: $10.1177 / 0192513 X_{13481332}$

Lemos, A.H.C., \& Cavazotte, F.S.C.N.(2018). É possível ter tudo? Carreira, maternidade e extensão da jornada na contemporaneidade. In: Carvalho Neto, A.; Versiani, F. (Eds.). Mulheres Profissionais: quem é o sexo frágil? Belo Horizonte: PUC-MINAS. p. 295.

Martins, S. S.V., Lipp, D. F.S., \& Monteiro Junior, R.C. T. (2020). Tempos de pandemia: Possibilidades para os trabalhadores na nova crise que se instala. Revista Valore, Volta Redonda, 5 (edição especial). 136-159. doi: 10.22408/reva502020653136-159

Melo, C., \& Cabral, S. (2020). A Grande Crise e as Crises Brasileiras: O Efeito Catalisador da Covid-19. Gestão e Sociedade, 14(39), 36813688. doi: 10.21171/ges.v14i39.3259

Melo, H.P., \& Thomé, D.(2018). Mulheres e poder. Rio de Janeiro: Editora FGV.

Mendes, D.C. Hastenreiter Filho, H. N. \& Tellechea, J. (2020). A realidade do trabalho home office na atipicidade pandêmica. Revista Valore, Volta Redonda, 5 (edição especial), 160-191. doi: 10.22408/ reva502020655160-191

Minnotte, K.L.(2012). Family structure, gender and the work-family interface: Work-to-family conflict among single and partnered parents. Journal of Family and Economic Issues, 33(1), 95-107. doi: 10.1007/s10834-011-9261-4

Netmeyer, R.G., Boles, J.S., \& McMurrian, R. (1996).Development and validation of work-family conflict and family-work conflict scales. Journal of Applied Psychology, 81(4), 400-410. doi: 10.1037/0021-9010.81.4.400

OIT (2017).Relatório da OIT destaca oportunidades e desafios na expansão do trabalho a distância. Recuperado de https:// nacoesunidas.org/trabalhando-a-qualquer-hora-em-qualquer-lugarnovo-relatorio-destaca-oportunidades-e-desafios-na-expansao-dotrabalho-a-distancia/

Oliveira, L.B., Cavazotte, F.S.C.N. \& Paciello, R. R. (2013). Antecedentes e consequências dos conflitos entre trabalho e família. Revista de Administração Contemporânea, 17(4), 418-437. doi: 10.1590/S141565552013000400003

OPAS (2020). Folha informativa - COVID 19 (doença causada pelo novo coronavírus). Recuperado de https://www.paho.org/bra/index.php?option $=$ com_content $\&$ view $=$ article $\& i d=6101$ : covid19\&Ite$\operatorname{mid}=875$

Peters, P., \& Blomme, R. J. (2019). Forget about 'the ideal worker': A theoretical contribution to the debate on flexible workplace designs, work/life conflict, and opportunities for gender equality. Business Horizons, 62, 603-613. doi: 10.1016/j.bushor.2019.04.003

Pluut, H., Ilies, R., Curseu, P.L. \& Liu, Y. (2018).Social support at work and ate home: Dual buffering effect in the work-family conflict process. Organizational Behavior and Human Decision Processes, 146, 1-13. doi: 10.1016/j.obhdp.2018.02.001 
Roman,C. (2017). Between money and love: work-family conflict among Swedish low-income single mothers. Nordic Journal of Working Life Studies, 7(3),23-41. doi: 10.18291/njwls.v7i3.97093

Savic, D. (2020). Covid 19 and work from home: Digital transformation of the workforce. The Grey Journal, 16(2), 101-104.

Santos, L. S.(2020). Dilemas Morais da Gestão Pública Brasileira no Enfrentamento da Pandemia do Novo Coronavírus. Revista de Administração Pública, 54(4), 909-922. doi: 10.1590/0034761220200219

Silva, M. F. G.(2020). Uma História sobre Pandemia (Covid-19), Isolamento e Fundamentos Microeconômicos de Políticas Públicas. Cadernos Gestão Pública e Cidadania, 25(80), 1-11. doi: $10.12660 /$ cgpc.v25n8o.81290

Costa, S. S. (2020). Pandemia e desemprego no Brasil. Revista de Administração Pública, v. 54(4), 969-978. doi: 10.1590/0034761220200170

Spurk, D.; Straub, C. (2020). Flexible employment relationships and careers in times of the COVID-19 pandemic. Journal of Vocational Behavior, 119, 1-4. doi: 10.1016/j.jvb.2020.103435
Tobias, P. B. (2020). Brasileiros estão mais estressados no home office. Recuperado de https://www.linkedin.com/feed/news/brasileirosest\%C3\%A3o-mais-estressados-no-home-office-4836924/

Trigo, L.G.G.(2020). Viagens e Turismo: Dos Cenários Imaginados às Realidades Disruptivas. Revista Brasileira de Pesquisa em Turismo, 14(3),1-13. doi: 10.7784/rbtur.v14i3.2107

Zhao, Y, Cooklin, A.R., Richardson, A, Strazdins, L, Butterworth P. , \& Leach L.S. 2020) Parent's shift work in connection with work-family conflict and mental health: examining the pathways for mothers and fathers. Journal of Family Issues,1-29. doi: 10.1177/0192513X20929059

Zerbini, T. \& Zerbini,T. (2020).Home office: O papel da ciência, orientações médicas e cuidados com o ambiente. In: Orientações para o Home office durante a Pandemia da COVID-19 - volume 1. SBPOT (1)Artmed Editora.

Waizenegger, L., McKenna, B., Cai, W. \& Bendz T. (2020).An affordance perspective of team collaboration and enforced working from home during Covid19. European Journal of Information Systems, 29(4), 429442. doi: $10.1080 / 0960085$ X.2020.1800417

\section{CONTRIBUIÇÃO DAS AUTORAS}

Ana Heloísa da Costa Lemos e Alane de Oliveira Barbosa trabalharam na conceitualização e abordagem teóricometodológica. A revisão teórica foi conduzida por Alane de Oliveira Barbosa. A coleta de dados foi coordenada por Priscila Pinheiro Monzato. Participaram da análise de dados Ana Heloísa da Costa Lemos, Alane de Oliveira Barbosa e Priscila Pinheiro Monzato. Todas as autoras participaram da redação e revisão final do manuscrito. 